\title{
Tendon Sheath Lipoma
}

National Cancer Institute

\section{Source}

National Cancer Institute. Tendon Sheath Lipoma. NCI Thesaurus. Code C6499.

A benign tumor, composed of mature adipocytes, that arises within the tendon sheath. 